\title{
Các yếu tố nguy cơ của tràn dịch màng ngoài tim cần dẫn lưu ở bệnh nhân sau phẫu thuật tim hở
}

\author{
Nguyễn Ngọc Yến Tuyêt", Lê Kim Tuyến
}

\section{TÓM TẮT}

Mục tiêu: xác định các yếu tố nguy cơ của tràn dịch màng ngoài tim cần dẫn lưu ở bệnh nhân sau phẫu thuật tim hở có mở màng ngoài tim.

Đối tượng và phương pháp nghiên cứu: 374 bệnh nhân từ 18 tuổi trở lên được phẫu thuật (PT) tim hở có mở màng ngoài tim tại Viện Tim TPHCM từ 01/07/2019 đến 17/12/2019. Tất cả đều được theo dõi 6 tháng kể từ lúc phẫu thuật. Nghiên cứu đoàn hệ hồi, tiến cứu.

Kết quả: Kết quả: tuổi trung bình: 50,3 \pm 12,7 , nam $46,3 \%$, nữ $53,7 \%$. Tràn dịch màng ngoài tim (TDMNT) nhiều cần dẫn lưu là $8,8 \%$, gồm chèn ép tim (CET) $3,5 \%$ và có khả năng CET 5,3\%. Thời điểm dẫn lưu trung bình là ngày hậu phẫu thứ $20,2 \pm 10,8$. Phân tích đơn biến cho thấy có 5 yếu tố nguy cơ có liên quan với TDMNT cần dẫn lưu sau PT tim hở: số lượng tiểu cầu trước $\mathrm{PT}$, rung nhĩ mới sau PT, nhóm NYHA (New York Heart Assocition) trước PT, INR tuần 2 và INR tuần 4 sau PT. Phân tích đa biến cho thấy có 4 yếu tố nguy cơ độc lập của TDMNT cần dẫn lưu sau PT tim hở: số lượng tiểu cầu trước PT, nhóm NYHA trước $\mathrm{PT}$, thời gian rút ống dẫn lưu màng tim và chỉ số INR tuần 2 sau PT.

Kết luận: sau PT tim hở, TDMNT nhiều cần dẫn lưu là $8,8 \%$. Số lượng tiểu cầu trước PT, nhóm NYHA trước PT, thời gian rút ống dẫn lưu màng tim và chỉ số INR tuần 2 sau $\mathrm{PT}$ là các yếu tố nguy cơ độc lập của TDMNT cần dẫn lưu.

Từ khóa: Tràn dịch màng ngoài tim, chèn ép tim, dẫn lưu, yếu tố nguy cơ.

\section{ABSTRACT \\ RISK FACTORS OF PERICARDIAL EFFUSIONS NEED TO BE DRAINED IN PATIENTS FOLLOWING OPEN HEART SURGERY}

Objectives: To define risk factors of pericardial effusions (PE) need to be drained in patients following open-heart surgery (OHS) with pericardial opening.

Methods: A retrospective and prospective cohort study of 374 consecutive patients aged 18 years or older who underwent OHS with pericardial opening at the Heart Institute of Ho Chi Minh City from July 1, 2019 to December 17, 2019. They are followed up for 6 months after surgery.

Results: the mean age: $50.3 \pm 12.7$, male $46.3 \%$, female $53.7 \%$. PE needed to be drained $8.8 \%$ that included cardiac tamponade in $3,5 \%$ and nearly tamponade in $5.3 \%$. The mean time from surgery to drain PE was 20,2 $\pm 10,8$ days after operation. Univariable analyses demonstrated 5 risk factors correlated with $\mathrm{PE}$ needed to be drained following open-heart surgery: preoperative platelet level, new postoperative atrial fibrillation, preoperative NYHA group, the $2^{\text {nd }}$ week and the $4^{\text {th }}$ week after surgery. Multivariable analysis found 4 independent risk factors correlated with $\mathrm{PE}$ needed to be drained following open-heart surgery: preoperative platelet level, preoperative NYHA group, time of the pericardial drains

Viện Tim TP HCM

*Tác giả liên hệ:

Nguyê̂n Ngọc Yến Tuyết- yentuyetnn@gmail.com-ĐT: 0919070245

Ngày nhận bài: 08/11/2021 Ngày Cho Phép Đăng:28/12/2021 
removal and the $2^{\text {nd }}$ week after surgery.

Results: after open-heart surgery, large PE needed to be drained were $8.3 \%$. Preoperative platelet level, preoperative NYHA group, time of the pericardial drains removal and the $2^{\text {nd }}$ week after surgery were independent risk factors of PE needed to be drained.

Keywords: pericardial effusion, cardiac tamponade, drainage, risk factor.

\section{1. ĐặT VẤN ĐỀ}

TDMNT là 1 biến chứng thường gặp sau PT tim hở do chảy máu sau PT hoặc do hội chứng sau mở màng ngoài tim (MNT) ${ }^{[2]}$. Chảy máu thường xảy ra trong một vài ngày đầu sau PT. Trái lại, TDMNT do hội chứng sau mở MNT thường gặp ở tuần thứ 2 sau PT nên còn được gọi là TDMNT muộn, được chẩn đoán dễ dàng bằng siêu âm. Nặng nề nhất là CET và có khả năng CET đòi hỏi phải dẫn lưu. TDMNT cần dẫn lưu tuy có tỷ lệ thấp $(6,2 \%)^{[3]}$ nhưng nếu không được chẩn đoán và xử trí kịp thời có thể dẫn đến tử vong. Trên thế giới, nhiều nghiên cứu đã tìm thấy một số YTNC của TDMNT cần dẫn lưu như PT bệnh van tim, thời gian chạy tuần hoàn ngoài cơ thể kéo dài, diện tích cơ thể $\geq 1,28 \mathrm{~m}^{2}$, dùng kháng vitamin $\mathrm{K}$ sau PT, NYHA III, IV... Chúng tôi thực hiện nghiên cứu này nhằm khảo sát TDMNT sau ngày hậu phẫu thứ 7 , các YTNC của TDMNT cần dẫn lưu ở bệnh nhân sau PT tim hở để phòng ngừa biến chứng này, giảm tử vong và cải thiện dự hậu cho bệnh nhân.

\section{2. ĐỐI TƯợNG VÀ PHƯƠNG PHÁP NGHIÊN CÚU}

2.1. Đối tượng nghiên cứu: 374 bn từ 18 tuổi trở lên được PT tim hở với tuần hoàn ngoài cơ thể, có mở màng ngoài tim tại Viện Tim TPHCM từ 01/07/2019 đến 17/12/2019.

2.2. Tiêu chuẩn loại trừ: $\mathrm{Bn}$ tử vong do mọi nguyên nhân trong tuần đầu sau PT, có chèn ép tim do chảy máu sau PT. tiến cứu.

2.3. Phương pháp nghiên cứu: Đoàn hệ hồi,

\section{KẾT QUẢ}

Tuổi trung bình: 50,3 $\pm 12,7(18-80)$. Nam 173 bn (46,3\%), nữ 201 bn $(53,7 \%)$. TDMNT cần dẫn lưu: $8,8 \%$ gồm có CET 3,5\% và có khả năng CET $5,3 \%$. CET gồm chèn ép thất phải $3 \%$, chèn ép nhĩ phải $0,5 \%$ (Bảng 1 ).

\section{Bảng 1. Đặc điểm chung của dân số nghiên cứu}

\begin{tabular}{|l|c|}
\hline \multicolumn{1}{|c|}{ Biến số } & Trung bình $(\min -\mathrm{max}) /$ \\
Số ca $(\%)(\mathrm{n}=374)$
\end{tabular}


Bảng 2. So sánh các biến định lượng giữa 2 nhóm có và không có TDMNT cần dẫn lưu

\begin{tabular}{|c|c|c|c|c|}
\hline \multirow[t]{2}{*}{ Yếu tố nguy cơ } & \multicolumn{2}{|c|}{ Dẫn lưu dịch MNT } & \multirow{2}{*}{ KTC 95\% } & \multirow{2}{*}{$\mathrm{p}$} \\
\hline & Có (n=33) & Không (n=341) & & \\
\hline Tuổi & $50,3 \pm 12,2$ & $50,3 \pm 12,8$ & $49-51,6$ & 0,9 \\
\hline $\operatorname{BSA}\left(\mathrm{m}^{2}\right)$ & $1,54 \pm 0,2$ & $1,56 \pm 0,2$ & $1,54-1,57$ & 0,7 \\
\hline BMI & $21,2 \pm 3,3$ & $21,9 \pm 3,4$ & $21,5-22,2$ & 0,2 \\
\hline EF trước PT (\%) & $63,8 \pm 12,3$ & $64,1 \pm 12,2$ & $62,8-65,3$ & 0,9 \\
\hline $\mathrm{Hb}$ trước $\mathrm{PT}(\mathrm{g} / \mathrm{dl})$ & $13,2 \pm 1,6$ & $13,3 \pm 1,5$ & $13,1-13,4$ & 0,8 \\
\hline Tiểu cầu trước PT $(K / \mu L)$ & $201,3 \pm 59,7$ & $245,5 \pm 70,4$ & $234,4-248,8$ & 0,001 \\
\hline Creatinine trước $\mathrm{PT}(\mu \mathrm{mol} / \mathrm{L})$ & $85,2 \pm 18,3$ & $84,8 \pm 18,7$ & $82,9-86,7$ & 0,9 \\
\hline Thời gian THNCT (phút) & $96,4 \pm 25,8$ & $102 \pm 38,5$ & $97,6-105,3$ & 0,4 \\
\hline Thời gian kẹp đmc (phút) & $61,7 \pm 19,8$ & $64,1 \pm 24,4$ & $61,4-66,3$ & 0,6 \\
\hline Thời gian rút ODL (giờ) & $30,4 \pm 13$ & $37,3 \pm 25,2$ & $34,2-39,2$ & 0,1 \\
\hline EF sau PT (\%) & $56,9 \pm 11,6$ & $60,4 \pm 12,4$ & $58,8-61,3$ & 0,1 \\
\hline INR ngày 7 sau PT & $2,4 \pm 1,1$ & $2,1 \pm 0,9$ & $2-2,2$ & 0,2 \\
\hline INR tuần 2 sau PT & $2,7 \pm 1$ & $2,2 \pm 0,9$ & $2,1-2,3$ & 0,004 \\
\hline INR tuần 3 sau PT & $2,4 \pm 1$ & $2,2 \pm 1,1$ & $2,1-2,3$ & 0,2 \\
\hline INR tuần 4 sau PT & $2,7 \pm 1,2$ & $2,2 \pm 1,1$ & $2,1-2,3$ & $\mathbf{0 , 0 1}$ \\
\hline INR tháng 3 sau PT & $2,2 \pm 0,9$ & $2 \pm 0,9$ & $1,9-2,1$ & 0,2 \\
\hline INR tháng 6 sau PT & $2 \pm 0,9$ & $1,8 \pm 1$ & $1,7-1,9$ & 0,3 \\
\hline
\end{tabular}

Chú thich: BSA (Body surface area: diện tích bề mặt co thể), BMI (Body mass index Chi số khối lượng cơ thể), ), EF (Ejection Fraction: phân suất tống máu), THNCT (tuần hoàn ngoài cơ thể), đmc (động mạch chủ), ODL (ống dẫn luu), INR (International normalized Ratio, chỉ số đông máu cho thuốc kháng vitamin $K)$.

Trong các biến định lượng, tiểu cầu trước PT, INR tuần 2 sau PT, INR tuần 4 sau PT có khác biệt có ý nghĩa thống kê giữa 2 nhóm có và không có TDMNT cần dẫn lưu. 


\section{Bảng 3. Phân tích đơn biến các biến định tính}

\begin{tabular}{|c|c|c|c|c|}
\hline \multirow{2}{*}{ Yếu tố nguy cơ } & \multicolumn{2}{|c|}{ Dẫn lưu dịch MNT (số ca,\%), n=374 } & \multirow{2}{*}{$\begin{array}{c}\text { OR } \\
\text { KTC 95\% }\end{array}$} & \multirow{2}{*}{$\mathrm{p}$} \\
\hline & Có (n=33) & Không $(\mathrm{n}=341)$ & & \\
\hline Rối loạn lipid máu & $9(2,4)$ & $101(27)$ & $0,9(0,4-1,9)$ & 0,9 \\
\hline Tăng huyết áp & $10(2,6)$ & $93(24,9)$ & $1,2(0,5-1,5)$ & 0,7 \\
\hline Đái tháo đường & $3(0,8)$ & $32(8,5)$ & $1(0,3-3,3)$ & 0,6 \\
\hline Rung nhĩ trước PT & $12(3,2)$ & $95(25,4)$ & $1,5(0,7-3,1)$ & 0,3 \\
\hline Nhóm NYHA trước PT & & & & \\
\hline$+\mathrm{NYHA} \leq \mathrm{II}$ & $25(6,6)$ & $298(79,7)$ & & \\
\hline$+\mathrm{NYHA}>\mathrm{II}$ & $8(2,1)$ & $43(11,6)$ & $2,2(0,9-5,2)$ & 0,1 \\
\hline Kháng vit $\mathrm{K}$ trước $\mathrm{PT}$ & $12(3,2)$ & $106(28,3)$ & $1,3(0,6-2,7)$ & 0,5 \\
\hline ASA trước PT & $7(1,8)$ & $71(18,9)$ & $1,02(0,4-2,5)$ & 0,9 \\
\hline Clopidogrel trước PT & $6(1,6)$ & $40(10,7)$ & $1,7(0,7-4,3)$ & 0,2 \\
\hline Statin trước PT & $10(2,6)$ & $96(25,7)$ & $1,1(0,5-2,4)$ & 0,8 \\
\hline Chẹn beta trước PT & $16(4,2)$ & $129(34,5)$ & $1,6(0,8-3,2)$ & 0,2 \\
\hline Kháng vit K sau PT & $29(7,8)$ & $259(69,3)$ & $2,3(0,8-6,7)$ & 0,1 \\
\hline ASA sau PT & $7(1,8)$ & $95(25,4)$ & $0,7(0,3-1,7)$ & 0,4 \\
\hline Clopidogrel sau PT & $2(0,5)$ & $28(7,5)$ & $0,7(0,2-3,2)$ & 0,5 \\
\hline Statin sau PT & $10(2.7)$ & $94(25,1)$ & $1,1(0,5-2,5)$ & 0,7 \\
\hline Chẹn beta sau PT & $16(4,2)$ & $175(46,8)$ & $0,9(0,4-1,8)$ & 0,8 \\
\hline Rung nhĩ mới sau PT & $4(1,1)$ & $13(3,5)$ & $3,5(1,1-11,4)$ & $\mathbf{0 , 0 4}$ \\
\hline
\end{tabular}

Hầu hết các yếu tố là biến định tính đều không có sự khác biệt giữa 2 nhóm có và không có TDMNT cần dẫn lưu. Rung nhĩ mới sau PT giữa 2 nhóm có và không có TDMNT có sự khác biệt có ý nghĩa thống kê với p=0,04. 
Bảng 4. Phân tích đơn biến các biến định lượng

\begin{tabular}{|c|c|c|c|}
\hline Yếu tố nguy cơ & B & OR (KTC 95\%) & $\mathrm{p}$ \\
\hline EF trước PT (\%) & $-0,002$ & $1(0,9-1)$ & 0,9 \\
\hline HB trước PT (g/dl) & 0,03 & $0,9(0,7-1,2)$ & $0,8(0,01)$ \\
\hline Tiểu cầu trước PT $(K / \mu L)$ & $-0,011$ & $0,98(0,9-1)$ & 0,001 \\
\hline Creatinine trước $\mathrm{PT}$ & 0,001 & $1(0,98-1)$ & 0,9 \\
\hline EF sau PT (\%) & $-0,02$ & $0,97(0,95-1)$ & 0,1 \\
\hline Thời gian rút ODL (giờ) & $-0,02$ & $0,98(0,96-1)$ & 0,1 \\
\hline INR ngày 7 sau PT & 0,24 & $1,3(0,91-1,78)$ & 0,15 \\
\hline INR tuần 2 sau PT & 0,51 & $1,7(1,17-2,36)$ & 0,005 \\
\hline INR tuần 3 sau PT & 0,19 & $1,2(0,89-1,64)$ & 0,2 \\
\hline INR tuần 4 sau PT & 0,35 & $1,4(1,08-1,47)$ & 0,01 \\
\hline INR tháng 3 sau PT & 0,24 & $1,3(0,86-1,87)$ & 0,2 \\
\hline INR tháng 6 sau PT & 0,19 & $1,2(0,85-1,72)$ & 0,3 \\
\hline
\end{tabular}

Số lượng tiểu cầu trước PT có tương quan nghịch với TDMNT cần dẫn lưu (tỷ số chênh OR 0,98, $\mathrm{p}=0,001)$. INR tuần 2 và tuần 4 sau PT có tương quan thuận với TDMNT cần dẫn lưu.

Bảng 5. Phân tích đa biến các yếu tố nguy cơ của TDMNT cần dẫn lưu

\begin{tabular}{|l|c|c|c|}
\hline Yếu tố nguy cơ & $\mathrm{B}$ & OR (KTC 95\%) & $\mathrm{p}$ \\
\hline Nhóm NYHA trước PT & 0,9 & $2,5(1-6,3)$ & 0,04 \\
Tiểu cầu trước PT & $-0,01$ & $0,9(0,98-1)$ & 0,001 \\
Thời gian rút ODL & $-0,29$ & $0,97(0,95-1)$ & 0,03 \\
INR tuần 2 sau PT & 0,44 & $1,6(1,06-2,3)$ & 0,03 \\
\hline
\end{tabular}

Bốn yếu tố nguy cơ có liên quan với TDMNT cần dẫn lưu: nhóm NYHA trước PT, tiểu cầu trước $\mathrm{PT}$, thời gian rút $\mathrm{ODL}$ và $\mathrm{INR}$ tuần 2 sau $\mathrm{PT}$

\section{BÀN LUậN}

Mặc dù có nhiều tiến bộ trong gây mê, PT và điều trị sau mổ, TDMNT vẫn còn là một biến chứng thường gặp sau $\mathrm{PT}$ tim hở có tuần hoàn ngoài cơ thể. Nghiên cứu của chúng tôi có 374 bn từ 18 tuổi trở lên. Qua 6 tháng theo dõi, không ca nào tử vong. Tuổi trung bình là $50,3 \pm 12,7(18-80)$ tuổi, nam $46,3 \%$, nữ $53,7 \%$. TDMNT cần dẫn lưu: $8,8 \%$ gồm có CET $3,5 \%$ và có khả năng CET 
$5,3 \%$. CET gồm chèn ép thất phải $3 \%$, chèn ép nhĩ phải $0,5 \%$. Nguyễn Sinh Hiền, tỷ lệ TDMNT cần dẫn lưu là $3,19 \%{ }^{[5]}$. Nina $\mathrm{K}$ Khan trên 1356 bn, TDMNT cần dẫn lưu là $6,2 \%$ (CET 4,1\%, có khả năng CET 2,1\%) ${ }^{[3]}$. PT bệnh van tim ưu thế $63,9 \%$, bắc cầu nối chủ vành $14,7 \%$, bệnh tim bẩm sinh $16 \%$, bệnh đmc $2,4 \%$, PT tim khác $3 \% . \%$. Khác với Nguyễn Sinh Hiền: PT bệnh van tim $45 \%$, bệnh bắc cầu nối chủ vành $6,8 \%$, bệnh tim bẩm sinh 44,8\%, bệnh động mạch chủ 1,6\%. Sự khác biệt này có thể do tuổi PT khác nhau. Thời điểm dẫn lưu trung bình là ngày hậu phẫu thứ $20,2 \pm 10,8$. So sánh 2 nhóm có dẫn lưu dịch MNT và nhóm còn lại ta thấy có một số yếu tố có sự khác biệt. Tiểu cầu là 1 yếu tố tham gia vào quá trình đông máu nội sinh. Ở nhóm có $\mathrm{DL}$, tiểu cầu trước PT trung bình $201,3 \pm 59,7 \mathrm{~K} / \mu \mathrm{L}$ thấp hơn nhóm không DL $(245,5 \pm 70,4 \mathrm{~K} / \mu \mathrm{L})$. Sự khác biệt này có ý nghĩa thống kê $(p=0,001)$. Dùng kháng vitamin $\mathrm{K}$ sau PT là 288 ca (77\%). Malouf $\mathrm{J} F$ cho rằng việc dùng kháng vitamin $\mathrm{K}$ sau PT làm tăng nguy cơ của TDMNT. TDMNT nhiều hoặc CET tăng đáng kể ở những bệnh nhân có dùng kháng đông sau PT ${ }^{[4]}$. Ở tuần thứ 2 sau $\mathrm{PT}$, INR ở nhóm có DL là $2,7 \pm 1$ cao hơn nhóm còn lại $(2,2 \pm 0,9)$ và tuần thứ 4 sau PT: INR ở nhóm có $\mathrm{DL}$ là $2,7 \pm 1,2$ cao hơn nhóm còn lại $(2,2 \pm 1,1)$, Sự khác biệt này có ý nghĩa thống kê (Bảng 2). Trong nghiên cứu, rung nhĩ mới sau PT cho cả 2 nhóm là $4,5 \%$. Khác với $M$. Chidombaram trên 242 bệnh nhân, tỷ lệ này là $8,7 \%{ }^{[1]}$. Trong phân tích đơn biến, rung nhĩ mới sau $\mathrm{PT}$ và $\mathrm{TDMNT}$ cần $\mathrm{DL}$ có liên quan $(\mathrm{p}=0,04$, $\mathrm{OR}=3,5, \mathrm{KTC}$ 95\% 1,1 -11,4). Rung nhĩ đòi hỏi phải dùng kháng vitamin $\mathrm{K}$. Có thể đây cũng là lý do góp phần làm cho rung nhĩ sau PT gây tăng nguy cơ TDMNT cần DL. Ngoài ra, tiểu cầu trước $\mathrm{PT}$, INR tuần 2 và $\mathrm{INR}$ tuần 4 sau $\mathrm{PT}$ cũng có mối liên quan với TDMNT cần $\mathrm{DL}$ với các giá trị p $<0,05$ (Bảng 4). Chúng tôi đưa các yếu tố có giá trị $\mathrm{p}<0,25$ từ các phân tích đơn biến vào phân tích hồi quy đa biến (Bảng 5). Kết quả cho thấy tiểu cầu trước PT là yếu tố nguy cơ độc lập với TDMNT cần DL (OR 0,99, KTC 95\% 0,98 $1, \mathrm{p}=0,001)$. Tiểu cầu có tương quan nghịch với TDMNT cần DL $(\mathrm{B}=-0,011)$. Số lượng tiểu cầu thấp sẽ làm tăng nguy cơ TDMNT cần DL. Phân loại nhóm suy tim theo NYHA là yếu tố nguy cơ độc lập với TDMNT cần DL (OR 2,5, KTC 95\% $1-6,3, p=0,04)$. NYHA III, IV làm tăng nguy cơ TDMNT cần DL lên 2,5 lần. Thời gian rút ODL màng tim trung bình ở nhóm có TDMNT cần $\mathrm{DL}$ là $30,4 \pm 13$ giờ và ở nhóm còn lại là $37,3 \pm 25,2$ giờ. Tiêu chuẩn rút ODL màng ngoài tim là khi lượng dịch dẫn lưu dưới $50 \mathrm{ml}$ trong 3 giờ, thông thường là trong ngày thứ $2 \mathrm{sau} \mathrm{PT}$. Thời gian rút ODL có thể kéo dài hơn nếu lượng dịch còn nhiều. Việc rút ODL màng ngoài tim sớm giúp giảm nguy cơ nhiễm trùng nhưng có thể làm tăng nguy cơ TDMNT nhiều hoặc CET đòi hỏi phải can thiệp xâm lấn ${ }^{[3]}$.Trong nghiên cứu, thời gian rút $\mathrm{ODL}$ màng tim là yếu tố nguy cơ độc lập với TDMNT cần DL (OR 0,97, KTC 95\% $0,95-1, p=0,03)$. Đây là tương quan nghịch. Thời gian rút $\mathrm{ODL}$ màng tim tăng lên 1 giờ sẽ làm giảm nguy cơ TDMNT cần $\mathrm{DL} 0,97$ lần. Ngoài ra, chỉ số INR tuần thứ 2 sau PT cũng là yếu tố nguy cơ độc lập với TDMNT cần DL (OR 1,56, KTC 95\% 1,06 - 2,30, p=0,02). INR tuần 2 tăng 1 đơn vị sẽ làm tăng nguy cơ TDMNT cần DL lên 1,56 lần.

\section{KẾT LUẬN}

Sau PT tim hở, TDMNT cần DL là $8,8 \%$

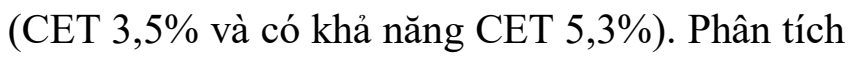
đơn biến có 4 yếu tố nguy cơ có liên quan với TDMNT cần DL: số lượng tiểu cầu trước $\mathrm{PT}$, rung nhĩ mới sau PT, INR tuần 2 và INR tuần 4 sau PT. Phân tích đa biến có 4 yếu tố nguy cơ độc lập của TDMNT cần DL: số lượng tiểu cầu trước $\mathrm{PT}$ và thời gian rút $\mathrm{ODL}$ (Tương quan nghịch), phân loại NYHA trước $\mathrm{PT}$ và chỉ số INR tuần 2 sau PT (Tương quan thuận). 


\section{TÀI LIỆU THAM KHẢO}

1. Chidambaram M., Akhtar M. J., alNozha M., et al. (1992). "Relationship of atrial fibrillation to significant pericardial effusion in valve-replacement patients". Thorac Cardiovasc Surg, 40 (2), pp. 70-3.

2. Floerchinger B., Camboni D., Schopka S., et al. (2013). "Delayed cardiac tamponade after open heart surgery - is supplemental CT imaging reasonable?". J Cardiothorac Surg, 8, pp. 158.

3. Khan N. K., Järvelä K. M., Loisa E. L., et al. (2017). "Incidence, presentation and risk factors of late postoperative pericardial effusions requiring invasive treatment after cardiac surgery". Interact Cardiovasc Thorac Surg, 24 (6), pp. 835-840.

4. Malouf j. F., Alam S., Stefadouros M. A. (1993). "The role of anticoagulation in the development of pericardial effusion and late tamponade after cardiac surgery". European Heart Journal, 14 (11), pp. 1451-1457.

5. Nguyen H. S., Nguyen H. D., Vu T. D. (2018). "Pericardial effusion following cardiac surgery. A single-center experience". Asian Cardiovasc Thorac Ann, 26 (1), pp. 5-10. 